\title{
Antibacterial Activity of Silver Nanoparticles Using Salvia officinalis Extract on Some Pathogenic Bacteria
}

\author{
Sarah Mohanad Yaseen, Asmaa A. Hussein and Ruqaya M. Al-Ezzy \\ Department of Molecular and Medical Biotechnology, College of Biotechnology, Al-Nahrain University, Baghdad, Iraq
}

\begin{abstract}
This study included evaluation for the effects of green synthetic nanoparticles of Salvia officinalis aqueous leaf extract loaded with silver nitrate on antibacterial activity. Green synthetic nanoparticles were synthesized by mixing the plant extract with different $\mathrm{AgNO}_{3}$ concentrations ( $1 \mathrm{mM}, 1.5 \mathrm{mM}, 1.75 \mathrm{mM}$, and $2 \mathrm{Mm}$ ) then they were detected by color changing and UV visible spectroscopy, which gave indication for the creation of silver nanoparticles. A characteristic and definite surface plasmon resonance (SPR) band for silver nanoparticles was obtained at around $433 \mathrm{~nm}$. The SPR peak of silver nanoparticles extreme peak intensity was obtained at $1.75 \mathrm{mM}$ of $\mathrm{AgNO}_{3}$. Atomic Force Microscopy analysis was used to characterize silver nanoparticles which declared that the shape of green synthetic nanoparticles had different average size depending on sliver concentrations. Since it was observed that the shape and size of green synthetic nanoparticles were concentrations dependent (89.69 nm, $80.94 \mathrm{~nm}, 76.98 \mathrm{~nm}$ and $60.28 \mathrm{~nm})$ respectively for $\mathrm{AgNO}_{3}$ concentrations tested $(1 \mathrm{mM}, 1.5 \mathrm{mM}, 1.75 \mathrm{mM}$ and $2 \mathrm{mM})$. The antibacterial activity of green synthetic sliver nanoparticles was studied for all G+ve and G-ve selected isolates (Staphylococcus aureus, Staphylococcus heamolytics, Streptococcus pnemoniae, Enterococcus faecalis) and others G-ve bacterial isolates (Escherichi coli, Klebsiella pneumoniae, Proteus vulgaris, Pseudomonas aeruginosa) and the result showed that different green synthetic nanoparticles concentrations $(1,1.5,1.75,2 \mathrm{mM})$ have the ability to inhibit all bacterial isolates with varying zones of inhibition higher than the inhibition observed by ready to use sliver nanoparticles. Minimum inhibitory concentrations (MIC) of green synthetic nanoparticles were obtained in concentration of (31, 27, 23 and $16 \mu \mathrm{m} / \mathrm{mL})$ for G+ve $(S$. auerus $)$ and $(187,125,125,109 \mu \mathrm{m} / \mathrm{mL})$ for G-ve (E. coli) at $(1,1.5,1.75,2$ mM) respectively. The activity of green synthetic sliver nanoparticles in inhibition $S$. auerus and E. coli, biofilm formation was studied and the result showed that $2 \mathrm{mM}$ nanoparticles could inhibit $75 \%$ of $S$. auerus biofilm and $50 \%$ of E. coli biofilm respectively.
\end{abstract}

Key words: Salvia officinalis, sliver nitrate, antibacterial, minimum inhibitory concentrations, biofilm.

\section{Introduction}

Salvia officinalis (Sage) is a popular food used as a therapeutic plant [1]. A decoction of sage leaves with wine was rinsed to remove toothache; it is used orally for gastrointestinal disorders, extreme perspiration, and was used topically for inflammation of the mucous membranes of the mouth and throat [2]; also, an infusion of the plant used to treat colds and coughs, and considered as antidiarrheal. Sage oil is mostly characterized by thujones, with $\alpha$-thujone usually predominating over $\beta$-thujone, camphor, 1,8-cineole, $\alpha$-humulene, $\alpha$-pinene, camphene, and bornyl acetate [3].

Corresponding author: Ruqaya M. AL-Ezzy, Ph.D., lecturer, research field: biotechnology.
Nanotechnology is the science of things and devices whose constructions and ingredients exhibit unique and considerably different physical, chemical and biological phenomenon cause to their nanoscale size [4]. Biosynthesis of green synthetic nanoparticles using plant extracts represents an interesting area in the field of nanotechnology, which has economic and ecofriendly benefits using physical and chemical. In the primary objective of nanotechnology especially used in cancer therapy is the improvement of appropriate targeting delivery systems which has been taking the lead in what concerns overcoming the Multidrug resistance (MDR) problem. Such targeted delivery systems that are based "Nanosizing" of drugs to decrease drug resistance and toxicity, reduce the dose needed, increase drug targeting ability, increase 
solubility, improve oral bioavailability and rate of dissolution, increase the stability of drug and formulation and increase patient compliance and surface area [5].

\section{Materials and Methods}

Silver nitrate, sage leaves, distill water.

\subsection{Methods}

\subsubsection{Plant Collection and Identification}

Salvia officinalis was collected from local market during October 2017 which was previously identified by national herbarium of Iraq. The dried leaves were grounded with a Wiley Mill grinder (Standard Model No. 3) into a fine powder and stored at sterile condition until use.

\subsubsection{Preparation of S. officinalis Aqueous Extract}

S. officinalis leaves $(50 \mathrm{~g})$ were washed out and soaked in one liter of distill water at $40{ }^{\circ} \mathrm{C}$ for $24 \mathrm{~h}$ with continuous stirring in shaking incubators. Then, the suspension was filtered through a cheese cloth in order to remove insoluble fragment, then, kept in refrigerator $4{ }^{\circ} \mathrm{C}$ for more studies [6].

\subsubsection{Biosynthesis of Sliver Nanoparticle [7]}

Silver nanoparticles were prepared using $S$. officinalis as plant source and sliver nitrate $\left(\mathrm{AgNO}_{3}\right)$ as silver source. Reaction mixtures were tested using 9 $\mathrm{mL}$ of different $\mathrm{AgNO}_{3}$ concentrations (1.0, 1.5, 1.75, and $2 \mathrm{mM}$ ) and $1 \mathrm{~mL}$ of sage extract, then incubated in the dark at $30{ }^{\circ} \mathrm{C}$ to evade the photo activation of silver nitrate under fixed conditions. S. officinalis extract as well as silver nitrate solution were used as control. All experiments were carried out in triplicates. The effect of the silver was determined by varying the $\mathrm{AgNO}_{3}$ concentration $(1.0,1.50,1.75$ or $2.0 \mathrm{mM})$ and sage concentration at $500 \mathrm{mg} / \mathrm{mL}$.

\subsection{Detection of Nanoparticles}

\subsubsection{Visual Observation}

NPs were characterized by color changing which is considered as an important method for early detection of synthetic green NPs [7].

\subsubsection{Spectrophotometer Reading}

Another method for detection of green synthetic nanoparticles was reading the absorbance by spectrophotometer at wavelength $433 \mathrm{~nm}$ [7].

\subsubsection{Atomic Force Microscopy [8]}

Atomic Force Microscopy (AFM) analysis was done using scanning prop microscopy NT-MTD. Samples of nanoparticles solution were diluted with distilled water, after that positioning on glass slide $(1 \times 1 \mathrm{~cm})$ and after drying the samples, the slide was put on the AFM sample stage and analysis was carried out according to the standard procedure.

\subsection{Antibacterial Activity}

2.3.1 Sample Collection and Isolation of G-ve and $\mathrm{G}+\mathrm{ve}$ Bacteria

A total of 105 specimens were collected from the urine, wound, respiratory tract, burn, blood and ear of the patients, from Al-yarmouk and Al-Karama Teaching Hospital in Baghdad during the period from $8 / 10 / 2017$ to $16 / 12 / 2017$. Swab specimens were aseptically transferred under cooling conditions to the laboratory for analysis.

Swabs were taken cautiously and placed in tubes containing transferred medium to maintain the swab wet during transferring to laboratory [9]. Each sample was inoculated on blood agar and MacConkey agar. All plates were incubated aerobically in an incubator at $37{ }^{\circ} \mathrm{C}$ for $24 \mathrm{~h}$. Then diagnosis of bacteria by cultural characteristics, microscopic examination, biochemical test and identification of bacteria by API 20 E system.

\subsubsection{Testing of Antibacterial Activity}

The cup-plate agar diffusion method was used to assess the antibacterial activity of green synthetic sliver nanoparticles, purchased from G-ve and G+ve bacterial isolates using sterile cotton swab dipped into fresh culture of bacteria $\left(10^{5}-10^{6} \mathrm{CFU} / \mathrm{mL}\right)$ and cultured three times by rotating the plate $60^{\circ}$ between streaking, $4-5$ cups, $10 \mathrm{~mm}$ in diameter were made in each muller hinton agar plate [10]. 
All cups were filled with $(75 \mu \mathrm{L})$ of different concentration nanoparticles $(1 \mathrm{mM}, 1.5 \mathrm{mM}, 1.75 \mathrm{mM}$, and $2 \mathrm{mM}$ ), S. officinalis used as control and incubated at $37{ }^{\circ} \mathrm{C}$ for 24 hours, after incubation the diameters of inhibition zone were measured.

\subsubsection{Minimum Inhibitory Concentration (MIC)}

The MIC values of green synthetic sliver nanoparticles were determined by broth microdilution assay. The green synthetic sliver nanoparticles with different concentrations $(1,1.5,1.75$, and $2 \mathrm{mM})$ were serially diluted. After shaking, $500 \mu \mathrm{L}$ of diluted Ag-NPs was added to each tube. Double Muller-Hinton broth was used as the broth medium. Microbial suspensions (E. coli and S. aureus) were adjusted to 0.5 MacFarland and diluted to $1 \times 10^{6} \mathrm{CFU} / \mathrm{mL}$, then 50 $\mu \mathrm{L}$ of the suspension was added to each tube and incubated at $37 \pm 2{ }^{\circ} \mathrm{C}$ for 24 hours. MIC values were determined as the lowest concentration of compound that inhibited bacteria after 24 hours [11].

2.3.4 Determination of Anti-biofilm Activity of Biosynthesized Green Synthetic Siver Nanoparticle

Biofilm formation tests were done using 96-well plate, based on the protocol described by Ref. [12], E. coli and S. aureus were cultivated in nutrient Broth overnight and the resulting culture was diluted to 1:100 (Trypton Soya Broth $+1 \%$ w/v glucose). Every well of plate full with $100 \mu \mathrm{L}$ of medium and $100 \mu \mathrm{L}$ of green synthetic nanoparticles, $200 \mu \mathrm{L}$ of medium used as control, then it was incubated at $37{ }^{\circ} \mathrm{C}$ for $24 \mathrm{~h}$. The bacteria were removed by shaking the dish over a waste tray filled with sterile distilled water, subsequently $0.1 \% \mathrm{w} / \mathrm{v}$ crystal violet solution was added to each well and the plate was gone to stain at room temperature. The used crystal violet solution was removed after 10 minutes by dipping the plate in a water tray, excess liquid was removed by inverting and topping the plate on paper towels and left to dry. The stained wells were treated with $95 \% \mathrm{v} / \mathrm{v}$ ethanol for 10 min at room temperature to solubilize the dye and optical density (OD) was measured in a micro plate reader at $530 \mathrm{~nm}$.

\section{Results and Discussion}

\subsection{Biosynthesis and Detection of Green Synthetic Sliver Nanoparticle}

The development of silver nanoparticles was monitored depending on color change and UV spectroscopy absorption. The color of the reaction mixture started changing from yellowish to dark brown after 1 hour (Fig. 1), representing the creation of silver nanoparticles, due to the reduction of silver metal ions $\mathrm{Ag}$ into silver nanoparticles Ag via the active molecules present in the S. officinalis extract. This color is attributed to the excitation of plasmon resonance property (SPR). A characteristic and well-defined SPR band for silver nanoparticles was obtained at around $433 \mathrm{~nm}$ (Fig. 2). The SPR peak of silver nanoparticles became distinct with enhancing the concentration of silver nitrate; the maximum peak intensity was obtained at $1.75 \mathrm{mM}$ of $\mathrm{AgNO}_{3}$.

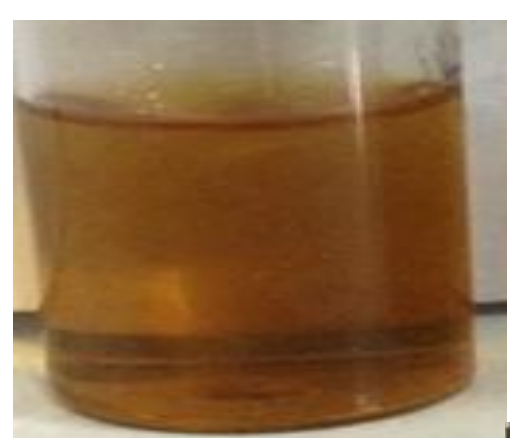

(A)

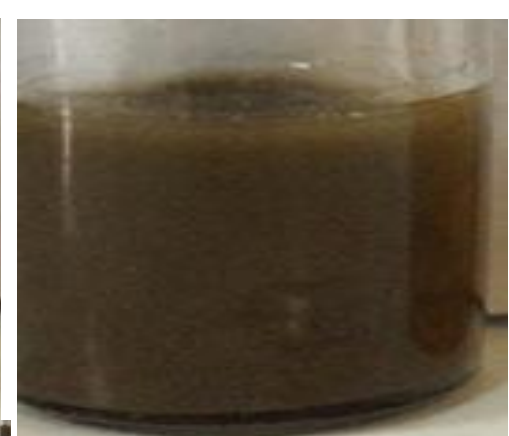

(B)

Fig. 1 Visual observation of synthesized green synthetic nanoparticles after $24 \mathrm{~h}$ where: (A) S. officinalis aqueous extract without $\mathrm{AgNO}_{3}$; (B) S. officinalis extract with sliver nanoparticles. 


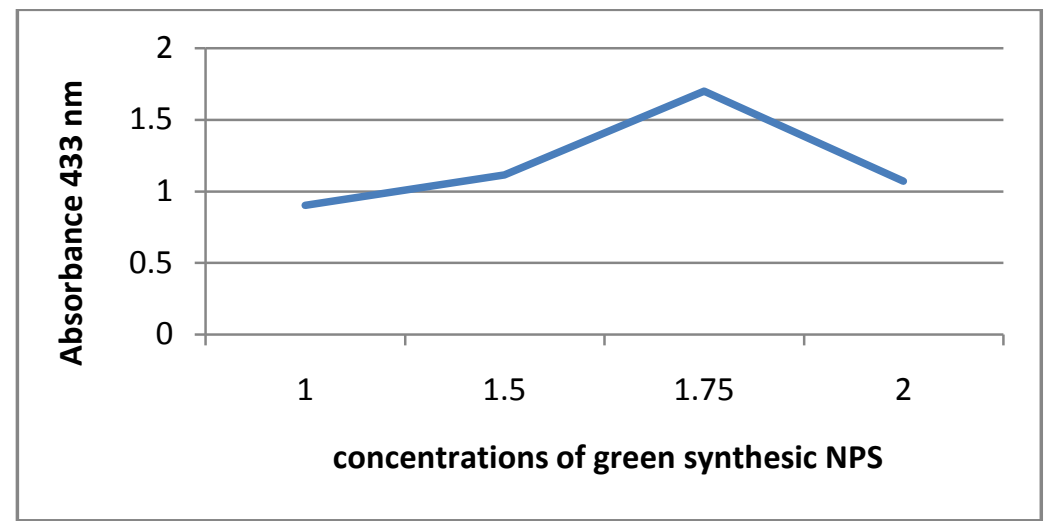

Fig. 2 UV visible absorption spectra of synthesized silver nanoparticles at $433 \mathrm{~nm}$.

\subsection{Characterization of Green Synthetic Silver} Nanoparticles

The form of the synthesized green synthetic silver nanoparticles was examined by AFM analysis which represented that the sliver nanoparticle had different average size depending on sliver concentrations (Fig. 3 A, B, C, and D). $\mathrm{AgNO}_{3}$ added to Salvia officinalis extract had many active small and large particles.

\subsection{Antibacterial Activity of Synthesized Sliver Nanoparticles}

According to the zone of inhibition, the antibacterial activity of green synthetic nanoparticles at $(1,1.5,1.75$, $2 \mathrm{mM}$ ) against $\mathrm{G}-\mathrm{ve}$ (E. coli, K. pneumonia, P. vulgaris, and $P$. aeruginosa) and G+ve ( $S$. aureus, $S$. heamolytics, S. pnemoniae, and E. faecalis) bacteria was studied. Results showed that green synthetic nanoparticles had effective antibacterial activity increased with increasing concentration on the tested G-ve bacteria (Fig. 4) with an inhibition zone ranged from 15 to $29 \mathrm{~mm}$ in diameter (Table 1). However, sliver nanoparticles alone showed lower antibacterial activity against the same G-ve bacteria (Fig. 5) with an inhibition zone ranged from 6 to $17 \mathrm{~mm}$ in diameter (Table 2). On the other hand, Fig. 6 showed that green synthetic NPs also, had antibacterial activity on G+ve bacteria with an inhibition zone ranged from 11 to 25 $\mathrm{mm}$ (Table 3) higher than the inhibition zone of sliver nanoparticles alone against the same tested bacteria (7) which ranged from 5 to 11 (Table 4).

\subsection{MIC of Green Synthetic Sliver Nanoparticle}

The antimicrobial activity of green synthetic silver nanoparticles was examined by means of MIC and biofilm formation against G (+) S. aureus and G (-) E. coli. After $24 \mathrm{~h}$ of incubation under aerobic situation at $37^{\circ} \mathrm{C}$, no turbidity was seen in all test tubes containing $S$. aureus and green synthetic nanoparticle with a concentration $(31,27,23$ and $16 \mu \mathrm{m} / \mathrm{mL})$ for $(1,1.5$, 1.75 and $2 \mathrm{mM}$ ) respectively (Table 5, Fig. 8). When bacterial growth of $E$. coli was assessed at different concentrations of green AgNPs after $24 \mathrm{~h}$, an MIC was observed in the range from $(187,125,125,109 \mu \mathrm{m} / \mathrm{mL})$ for $(1,1.5,1.75$ and $2 \mathrm{mM}$ ) respectively (Table 6, Fig. 9).

\subsection{Biofilm Formation Inhibition}

The results of in vitro biofilms inhibition action of green synthetic AgNPs were presented in Fig. 10. Biofilm reduction assay results showed that Ag-NPs at $2 \mathrm{mM}$ could inhibit $75 \%$ of $S$. aureus biofilm, while the inhibition was decreased to $35 \%$ of biofilm formation at $1 \mathrm{mM}$. Moreover, the biofilm decrease assay results presented that green synthetic Ag-NPs at $2 \mathrm{mM}$ inhibited $50 \%$ of E. coli biofilm formation $25 \%$ of biofilm formation was inhibited at $1 \mathrm{mM}$.

The mechanism of resistance of bacterial biofilms has yet to be explained but a possibly main reason is creation of the glycocalyx which permits cells rising within the biofilm to avoid host defenses and the action of antibacterial agents [13]. 


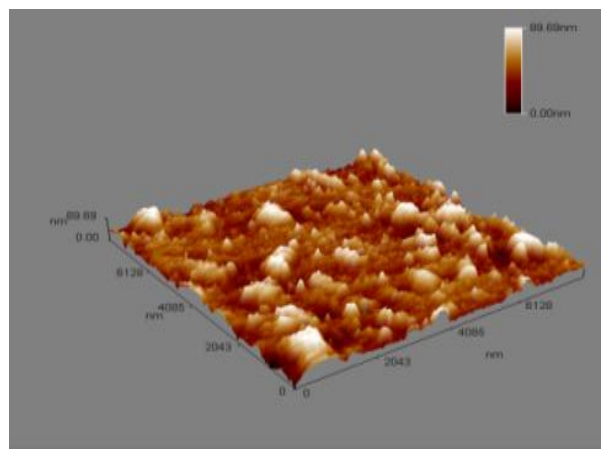

(A)

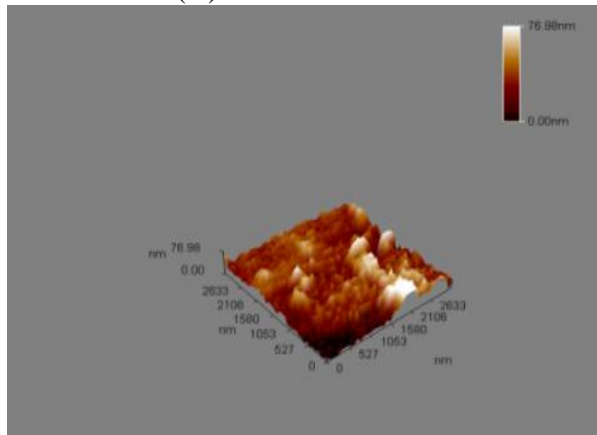

(C)

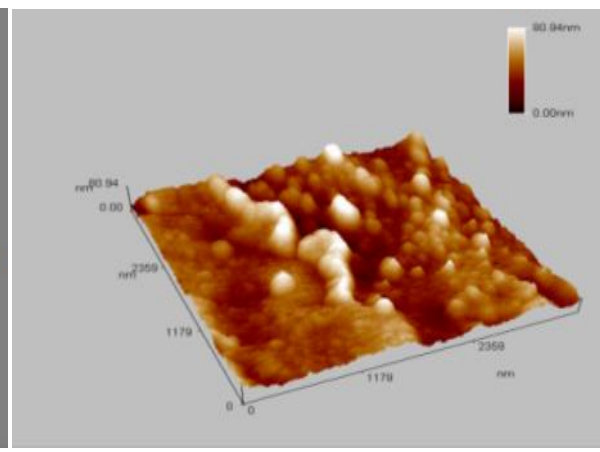

(B)

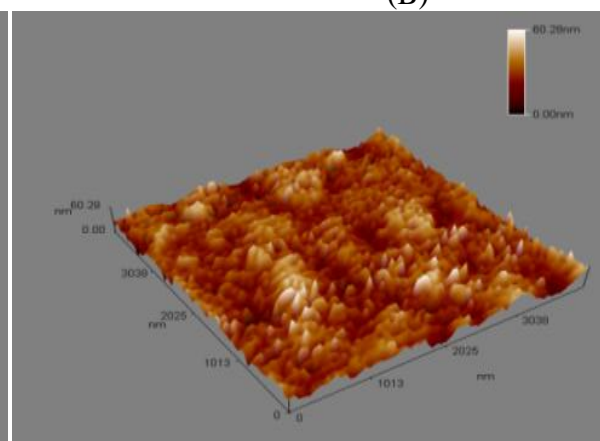

(D)

Fig. 3 AFM sections of green synthetic Ag nanoparticles using different concentrations where: (A) 1 mM of green synthetic NPs with 89.69 $\mathrm{nm}$ average size; (B) $1.5 \mathrm{mM}$ of green synthetic NPs with $80.94 \mathrm{~nm}$ average size; (C) $1.75 \mathrm{mM}$ of green synthetic NPs with $76.98 \mathrm{~nm}$ average size; (D) $2 \mathrm{mM}$ of green synthetic NPs with $60.28 \mathrm{~nm}$ average size.

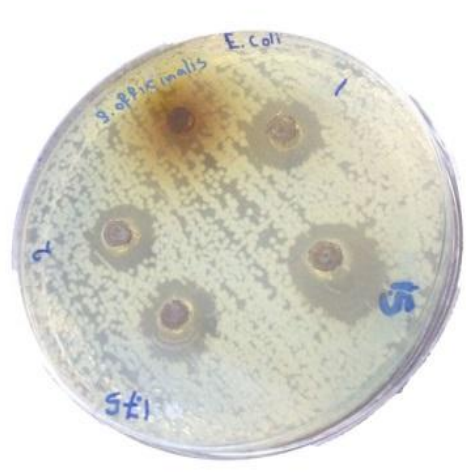

E. coli

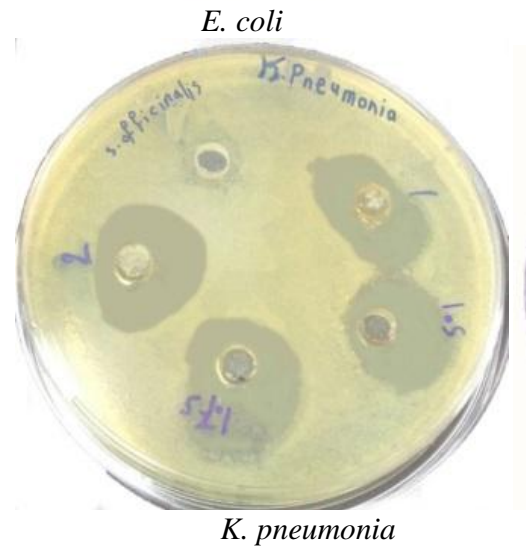

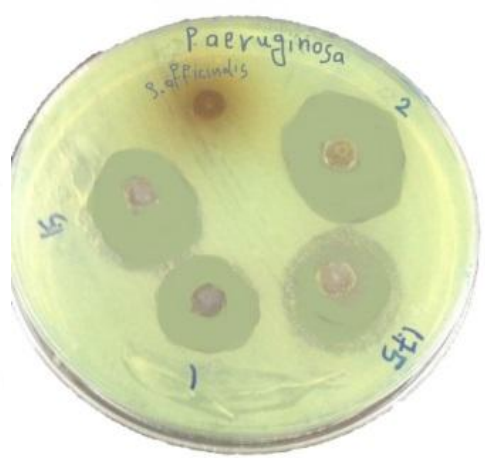

P. aeruginosa

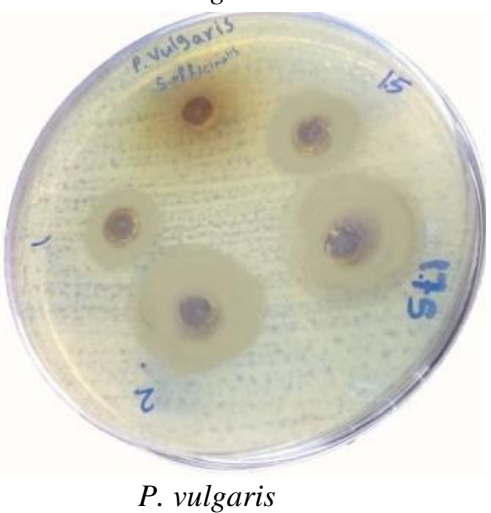

Fig. 4 Antibacterial activity (zone of inhibitions) of green synthetic sliver nanoparticles (1, 1.5, 1.75, 2 mM) against Gram negative bacterial isolates (E. coli, P. aeruginosa, K. pneumonia, P. vulgaris). 
Table 1 Zone of inhibition (in mm) produced by green synthetic silver nanoparticles (1 mM, $1.5 \mathrm{mM}, 1.75 \mathrm{mM}, 2 \mathrm{mM})$ on Gram (-) tested bacteria, $S$. officinalis used as a control.

\begin{tabular}{lllll}
\hline $\begin{array}{l}\text { Concentrations of green synthetic sliver } \\
\text { nanoparticles }\end{array}$ & E. coli & P. aeruginosa & K. pneumonia & P. vulgaris \\
\hline $1 \mathrm{mM}$ & 15 & 20 & 19 & 15 \\
$1.5 \mathrm{mM}$ & 17 & 25 & 20 & 17 \\
$1.75 \mathrm{mM}$ & 19 & 29 & 22 & 25 \\
$2 \mathrm{mM}$ & 22 & 29 & 22 & 25 \\
S. officinalis $(500 \mathrm{mg} / \mathrm{mL})$ & - & - & - & - \\
\hline
\end{tabular}

*All values represented in the table are average of results of three separately conducted experiments.

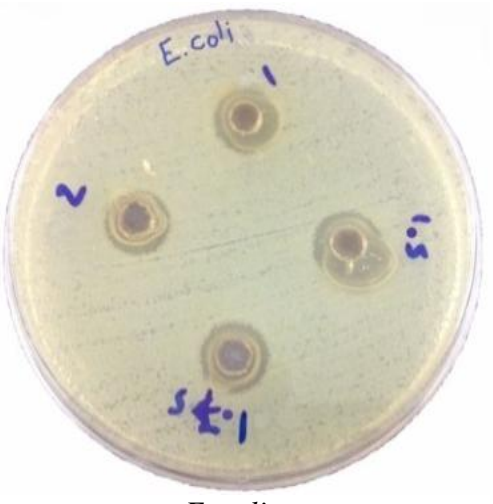

E. coli

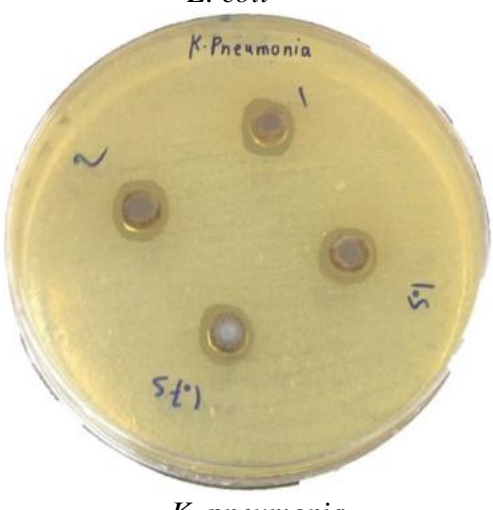

K. pneumonia

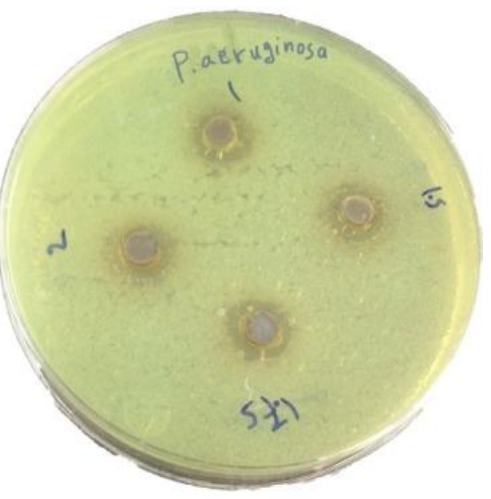

P. aeruginosa

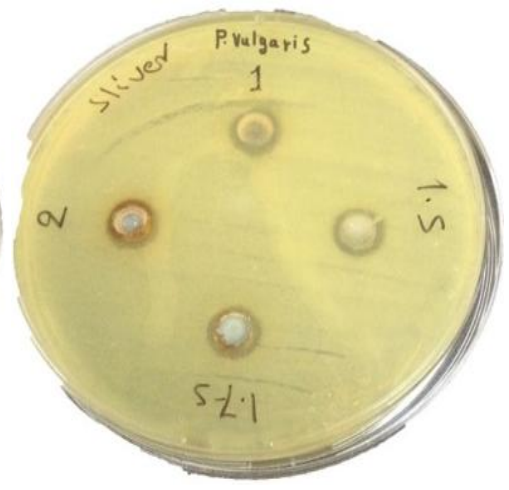

P. vulgaris

Fig. 5 Antibacterial activity (zone of inhibitions) of ready to use sliver nanoparticles (1 mM, $1.5 \mathrm{mM}, 1.75 \mathrm{mM}, 2 \mathrm{mM})$ on bacterial isolates (E. coli, P. aeruginosa, K. pneumonia, P. vulgaris).

Table 2 Zone of inhibition (in $\mathrm{mm}$ ) produced by ready to use sliver nanoparticles (1 mM, $1.5 \mathrm{mM}, 1.75 \mathrm{mM}, 2 \mathrm{mM})$ on Gram (-) tested bacteria.

\begin{tabular}{lllll}
\hline Concentrations of sliver nanoparticles & E. coli & P. aeruginosa & K. pneumonia & P. vulgaris \\
\hline $1 \mathrm{mM}$ & 12 & 9 & 8 & 6 \\
$1.5 \mathrm{mM}$ & 13 & 9 & 8 & 6 \\
$1.75 \mathrm{mM}$ & 15 & 10 & 9 & 8 \\
$2 \mathrm{mM}$ & 17 & 12 & 12 & 10 \\
\hline
\end{tabular}

*All values represented in the table are average of results of three separately conducted experiments. 


\section{Extract on Some Pathogenic Bacteria}
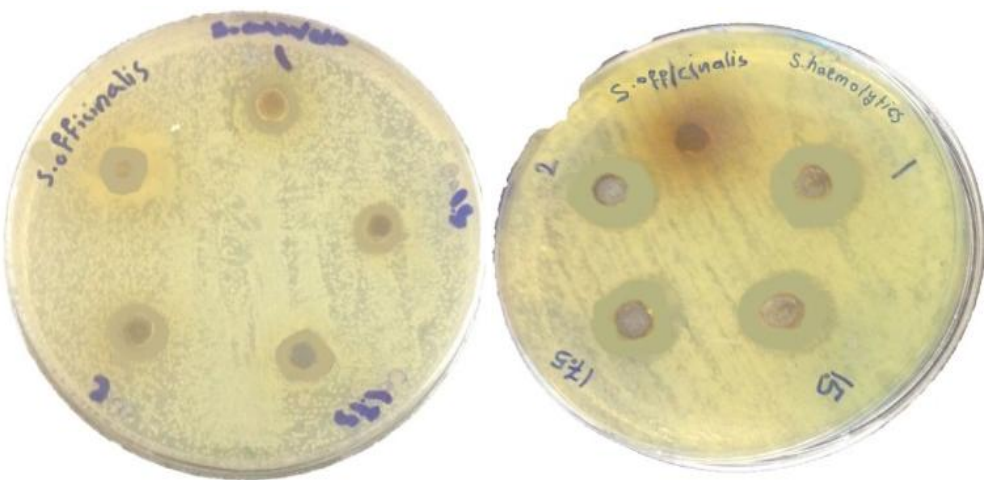

S. aureus

S. haemolyticus
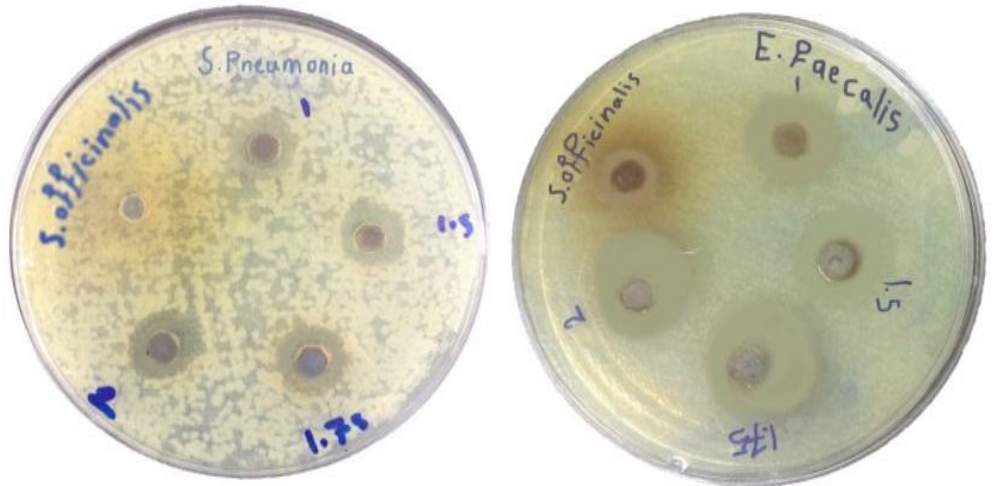

S. pneumonia

E. faecalis

Fig. 6 Antibacterial activity (zone of inhibitions) of green synthetic sliver nanoparticles (1, 1.5, 1.75, 2 mM) against Gram positive tested bacteria (S. aureus, S. haemolyticus, S. pneumonia, E. faecalis).

Table 3 Zone of inhibition (in mm) produced by green synthetic silver nanoparticles (AgNPs) (1 mM, $1.5 \mathrm{mM}, 1.75 \mathrm{mM}$, and $2 \mathbf{m M}$ ) on Gram (+) test organisms, $S$. officinalis used as a control.

\begin{tabular}{lllll}
\hline $\begin{array}{l}\text { Concentrations of green synthetic sliver } \\
\text { nanoparticles }\end{array}$ & S. aureus & S. heamolytics & S. pnemoniae & E. faecalis \\
\hline $1 \mathrm{mM}$ & 11 & 17 & 11 & 19 \\
$1.5 \mathrm{mM}$ & 11 & 19 & 12 & 20 \\
$1.75 \mathrm{mM}$ & 15 & 20 & 14 & 22 \\
$2 \mathrm{mM}$ & 16 & 20 & 15 & 25 \\
S. officinalis $(500 \mathrm{mg} / \mathrm{mL})$ & 11 & - & - & 15 \\
\hline
\end{tabular}

*All values represented in the table are average of results of three separately conducted experiments.

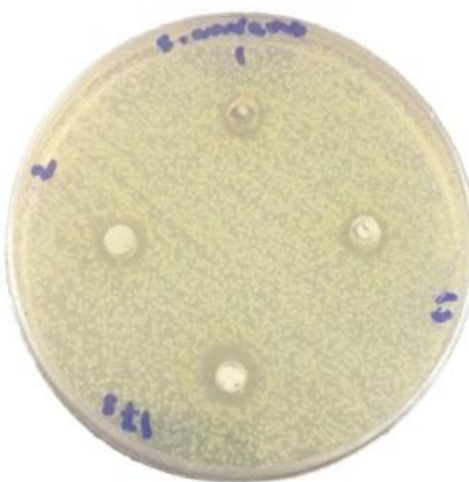

S. aureus

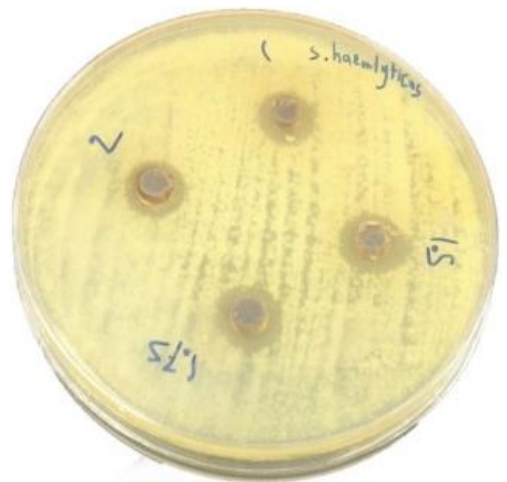

S. haemolyticus 


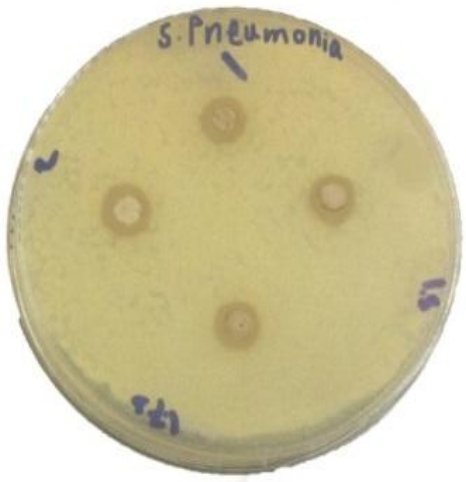

S. pneumonia

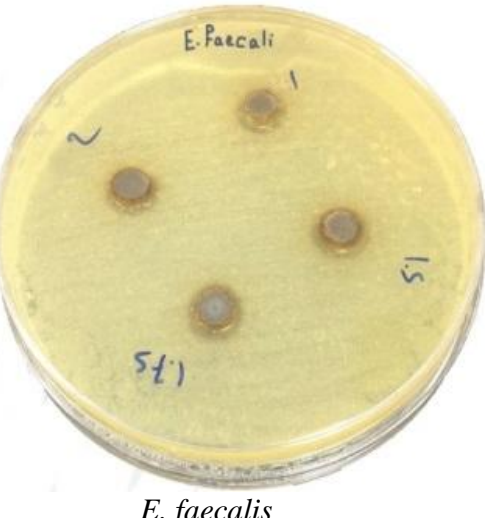

E. faecalis

Fig. 7 Antibacterial activity (zone of inhibitions) of ready to use sliver nanoparticles (1 mM, $1.5 \mathrm{mM}, 1.75 \mathrm{mM}$, and $2 \mathrm{mM}$ ) on Gram positive tested bacteria (S. aureus, S. haemolyticus, S. pneumonia, E. faecalis).

Table 4 Zone of inhibition (in $\mathrm{mm})$ produced by ready to use sliver nanoparticles (1 mM, $1.5 \mathrm{mM}, 1.75 \mathrm{mM}, 2 \mathrm{mM})$ on Gram (+) tested bacteria.

\begin{tabular}{lllll}
\hline Concentrations of sliver nanoparticles & S. aureus & S. heamolytics & S. pneumonia & E. faecalis \\
\hline $1 \mathrm{mM}$ & 8 & 9 & 6 & 5 \\
$1.5 \mathrm{mM}$ & 8 & 10 & 6 & 8 \\
$1.75 \mathrm{mM}$ & 9 & 10 & 7 & 9 \\
$2 \mathrm{mM}$ & 10 & 11 & 9 & 9 \\
\hline
\end{tabular}

*All values represented in the table are average of results of three separately conducted experiments.

Table 5 A minimum inhibitory concentration of green synthetic sliver nanoparticles for $S$. auerus after 24 hrs incubation at $37^{\circ} \mathbf{C}$.

\begin{tabular}{ll}
\hline Concentrations of green synthetic silver nanoparticles $(\mathrm{mM})$ & Minimum inhibitory concentrations $(\mu \mathrm{m} / \mathrm{mL})$ \\
\hline $1 \mathrm{mM}$ & 31 \\
$1.5 \mathrm{mM}$ & 27 \\
$1.75 \mathrm{mM}$ & 23 \\
$2 \mathrm{mM}$ & 16 \\
\hline
\end{tabular}

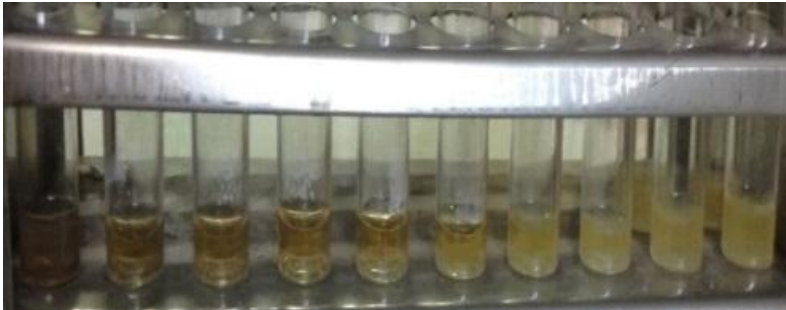

(A)

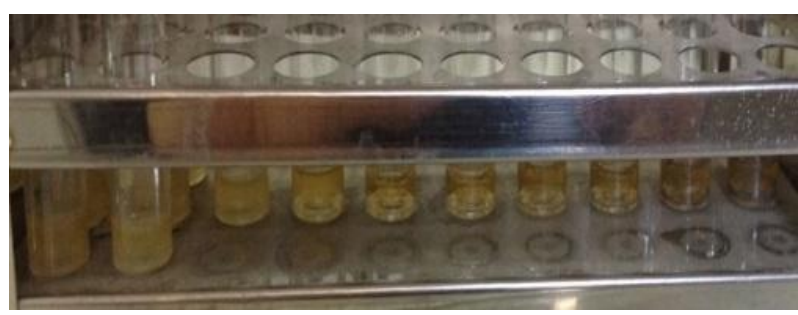

(C)

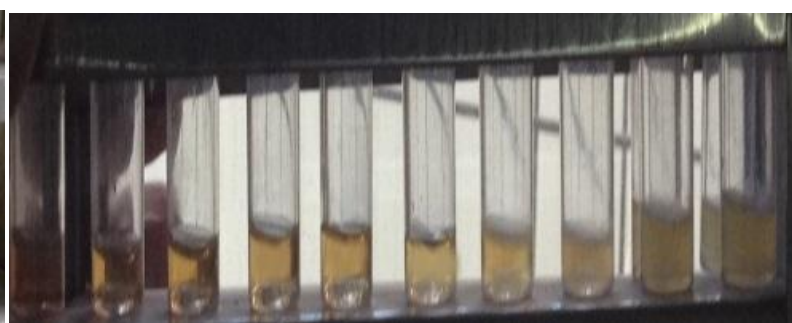

(B)

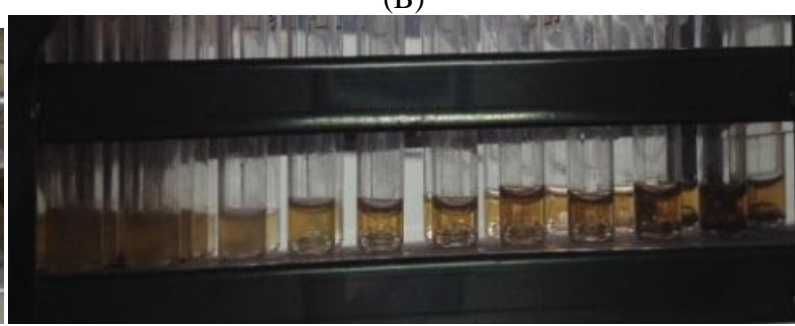

(D)

Fig. 8 Turbidity of $S$. aureus bacterial growth with different concentrations (1 mM, $1.5 \mathrm{mM}, 1.75 \mathrm{mM}$, and $2 \mathrm{mM})$ of green synthetic NPs after incubation at $37^{\circ} \mathrm{C}$ for $24 \mathrm{~h}$ : (A) $31 \mu \mathrm{M}(1 \mathrm{mM})$; (B) $27 \mu \mathrm{M}(1.5 \mathrm{mM})$; (C) $23 \mathrm{mM}$ (1.75 mM); (D) for $16 \mu \mathrm{M}$ (1.5 mM). 
Table 6 A minimum inhibitory concentration of green synthetic sliver nanoparticles for $E$. coli after $24 \mathrm{~h}$ incubation at $37^{\circ} \mathrm{C}$.

\begin{tabular}{ll}
\hline Concentrations of green synthetic silver nanoparticles $(\mathrm{mM})$ & Minimum inhibitory concentrations $(\mu \mathrm{m} / \mathrm{mL})$ \\
\hline $1 \mathrm{mM}$ & 187 \\
$1.5 \mathrm{mM}$ & 125 \\
$1.75 \mathrm{mM}$ & 125 \\
$2 \mathrm{mM}$ & 109 \\
\hline
\end{tabular}

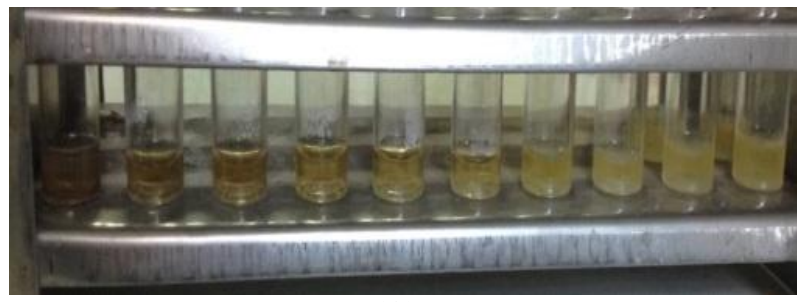

(A)

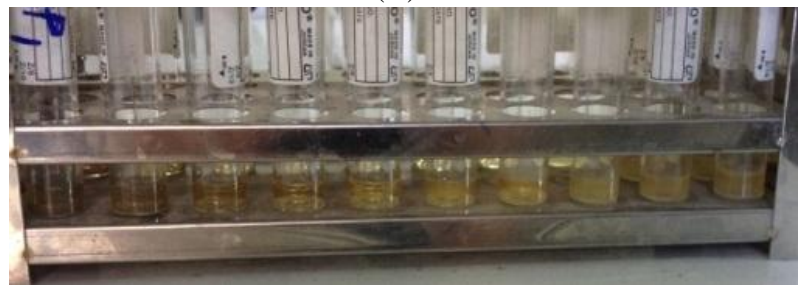

(C)

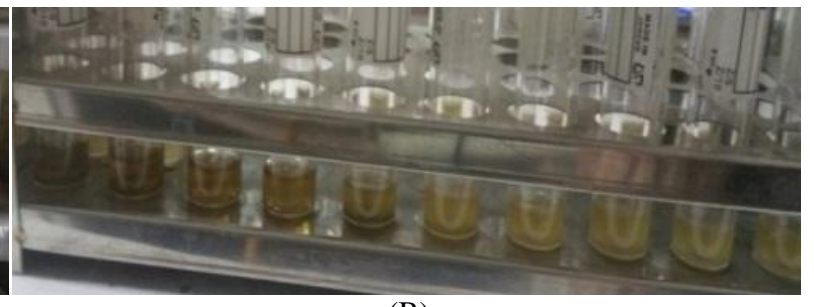

(B)

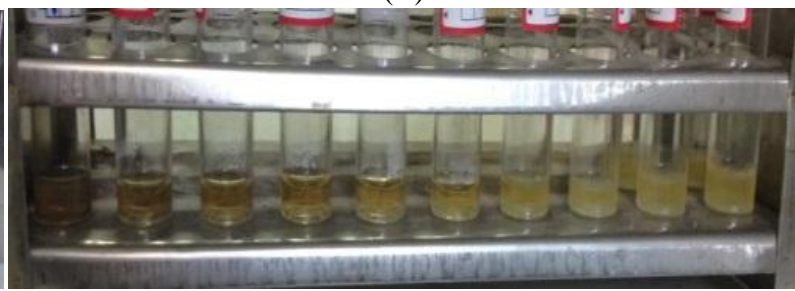

(D)

Fig. 9 Turbidity of $E$. coli bacterial growth with different concentrations (1 mM, $1.5 \mathrm{mM}, 1.75 \mathrm{mM}$, and $2 \mathrm{mM})$ of green synthetic NPs after incubation at $37{ }^{\circ} \mathrm{C}$ for $24 \mathrm{~h}$ : (A) $187 \mu \mathrm{M}(1 \mathrm{mM})$; (B) $125 \mu \mathrm{M}$ (1.5 mM); (C) $125 \mu \mathrm{M}$ (1.75 mM); (D) 109 $\mu \mathrm{M}(2 \mathrm{mM})$.

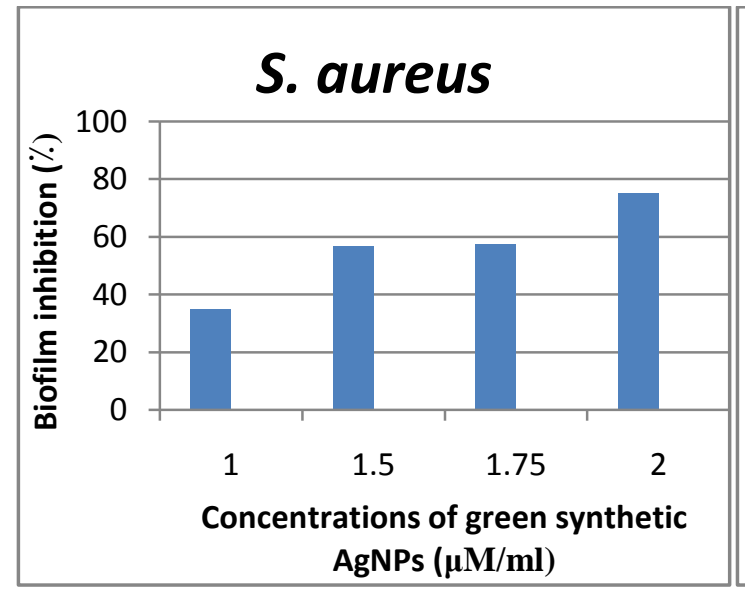

(A)

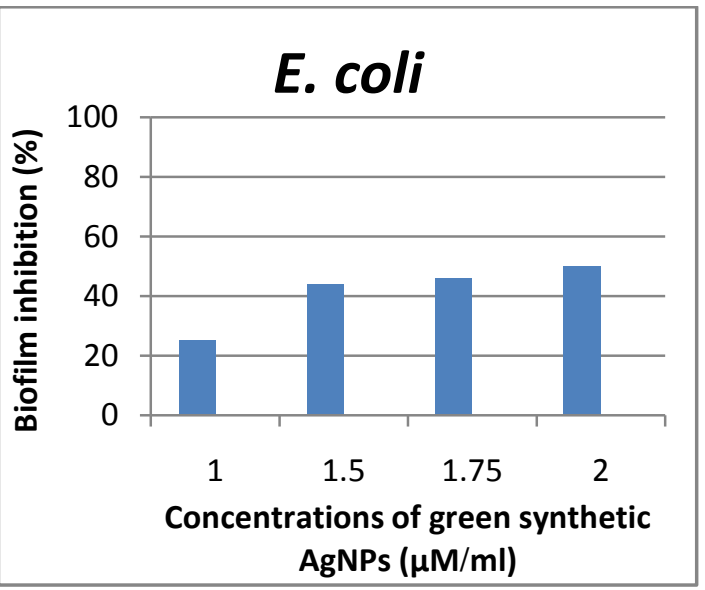

(B)

Fig. 10 Dose-dependent effects of green synthetic AgNPs on bacterial biofilm formation.

where A: S. aureus; B: E. coli.

\section{Discussion}

It has been well documented that green synthetic sliver nanoparticles exhibit brown color in aqueous solution due to excitation of surface plasmon vibrations [14]. On the other hand, a difference in the biological material and metal salt concentration is known to affect nanoparticle synthetic. The noble metals are known to possess unique optical characteristics due to surface plasmon resonance property (SPR), some scientists suggested that the ability of $S$. officinalis extract to synthesize AgNPs [15] might be attributed to plant secondary metabolites such as phenolic compounds and organic acids [16]. In another study submitted by Ref. [17], they founded that reduction of $\mathrm{AgNO}_{3}$ to silver by plants is due to the presence of some chemical 
compound which acts as reducing agent for generation of electron. While, Ref. [18] declared that the presence of polyphenolic compounds in S. officinalis leaves extract acts as a reducing agent for the transformation of silver sulphate into silver nanoparticles. Phenolic diterpenoids extracted from the plant showed a strong anti-oxidant activity [19] and these compounds are effective in scavenging free radicals [20]. Further studies discovered that natural products such as flavonoids and phenolics have been observed to be capable free radical scavengers and lipid peroxidation inhibitors [21]. Accordingly, there is increasing interest in the potential health benefits of dietary flavonoids, and the present study shared such interest in investigating the anti-oxidant and radical scavenging activity of S. officinalis methanol extract, because of its richness in flavonoids [22]. The bioreduction of aqueous silver ions by the plant extract of $S$. officinalis extract is a good source for green chemistry approach towards the synthesis of silver nanoparticles which has many advantages such as, ease with which the process can be scaled up, economic feasibility, etc. [23].

Gram negative bacteria displayed greater zones of inhibition, when compared with the Gram positive bacteria, which may be due to the variation in cell wall composition [24]. The cell wall of Gram positive bacteria consists of a thick peptidoglycan layer, having of linear polysaccharide chains cross linked by short peptides, thus creating more severe structure leading to firm penetration of the silver nanoparticles, while in Gram negative bacteria the cell wall owns thinner peptidoglycan layer [25]. On the other hand, numerous chief mechanisms underlie the biocidal properties of silver nanoparticles against microorganisms. The first one proposed that when silver nanoparticles attach to the negatively charged cell surface alter the physical and chemical properties of the cell membranes, the cell wall and disturb important functions such as permeability, osmoregulation, electron transport and respiration [26]. The second one stated that silver nanoparticles can basis further destruction to bacterial cells by infusing the cell, where they relate with DNA, proteins and other phosphorus- and sulfur-containing cell ingredients [27]; while the third one in silver nanoparticles release silver ions, generating an amplified biocidal effect, which is size- and dose-dependent [28].

Another, reported effective antimicrobial activity of silver nanoparticles against E. coli and S. aureu [29]. In 2017, some scientists used silver nanoparticles against Gram-Positive and Gram-Negative Bacteria [30]. Also, antimicrobial activity of biosilver nanoparticles produced by a novel Streptacidiphilus durhamensis strain was measured [31].

Some researchers exposed that some non-toxic antibiofilm (antivirulence) composites exist in some plant extraction including brominated furanones, ursolic acid, indole derivatives and 5-fluorouracil had antibiofilm activity for E. coli [32] while Ref. [33] stated that the making of biofilms in E. coli, S. aureus, Salmonella typhii and Vibrio cholerae was inhibited by silver nanoparticles. Also, in 2012 some studies on the effects of silver nanoparticles alone and in combination with several antibiotics made a complete inhibition of biofilm which was observed within 24 hours, as well as a good compatibility with combination of silver nanoparticles and antibiotics to inhibit biofilm [34].

\section{References}

[1] Craft, J. D., Satyal, P., and Setzer, W. N. 2017. "The Chemotaxonomy of Common Sage (Salvia officinalis) Based on the Volatile Constituents." Medicines 29: 3-4.

[2] Pelkonen, O., Abass, K., and Wiesner, J. 2013. "Thujone and Thujone-containing Herbal Medicinal and Botanical Products: Toxicological Assessment." Regul Toxicol Pharmacol 65: 100-7.

[3] Ghorbani, A., and Esmaeilizadeh, M. 2017. "Pharmacological Properties of Salvia officinalis and Its Components." J Tradit Complement Med. 7 (4): 433-40.

[4] Khan, I., Saeed, K., and Khan, I. 2017. "Nanoparticles: Properties, Applications and Toxicities." Arab Jchem. https://doi.org/10.1016/j.arabjc.2017.05.011.

[5] Mahajan, S. D., Roy, I., Xu, G., Yong, K., Ding, H., and Aalinkeel, R. 2010. "Enhancing the Delivery of Antiretroviral Drug 'Saquinavir' across the Blood Brain 


\section{Extract on Some Pathogenic Bacteria}

Barrier Using Nanoparticles.” Curr HIV Res. 9: 396-404.

[6] Kadhim, S. M., Mohammed, M. T., Ahmed O. M., and Jassimand, A. M. N. 2016. "Study of Some Salvia officinalis L. (Sage) Components and Effect of Their Aqueous Extract on Antioxidant." Int J Chem Sci. 14 (2): 711-9.

[7] Ibrahim, H. M. M. 2015. "Green Synthesis and Characterization of Silver Nanoparticles Using Banana Peel Extract and Their Antimicrobial Activity against Representative Microorganisms." Journal of Radiation Research and Applied Sciences 8: 265-75.

[8] Nishida, S., Kobayashi, D., Sakurada, T., Nakazawa, T., Hoshi, Y., and Kawakatsu, H. 2008. "Photothermal Excitation and Laser Doppler Velocimetry of Higher Cantilever Vibration Modes for Dynamic Atomic Force Microscopy in Liquid." Rev Sci Instrum. 79: 12.

[9] MacFaddin, J. F. 2000. Biochemical Tests for the Identification of Medical Bacteria. New York: Williams and Wilkins (Ed.).

[10] Ruth, E., and Miller, S. 2015. "Brandt Rose." Am J Clin Pathol. 11 (1): 414-24.

[11] Baker, C. N., Thornsberry, C., and Hawkinson, R. W. 1983. "Inoculum Standardization in Antimicrobial Susceptibility Tests: Evaluation of the Use of Overnight Agar Cultures and the Rapid Inoculum Standardization System." Clin Microbiol. 17: 450-7.

[12] Goh, H. M., Beatson, S. A., Totsika, M., Moriel, D. G., Phan, M. D., Szubert, J., Runnegar, N., Sidjabat, H. E., Paterson, D. L., Nimmo, G. R., Lipman, J., and Schembri, M. A. 2013. "Molecular Analysis of the Acinetobacter Baumannii Biofilm-associated Protein." Appl Environ Microbiol. 79: 6535-43.

[13] Ramachandran, R., and Sangeetha, D. 2017. "Antibiofilm Efficacy of Silver Nanoparticles against Biofilm Forming Multidrug Resistant Clinical Isolates." J Pharm Innov. 6 (11): 36-43.

[14] Daoud, S., Alqahtani, M. A. M., Alkhalifah, D. H. M., Elobeid, M. M., and Mohammed, A. E. 2015. "Biosynthesis of Silver Nanoparticles Using Salvia officinalis Extract and Assessment of Their Antibacterial Activity.” Int J Curr Res. 7 (10): 21548-52.

[15] Bindhu, M. R., and Umadevi, M. 2013. "Synthesis of Monodispersed Silver Nanoparticles Using Hibiscus Cannabinus Leaf Extract and Its Antimicrobial Activity." Spectrochim Acta A Mol Biomol Spectrosc. 101: 184-90.

[16] Prabhu, S., and Poulose, E. K. 2012. "Silver Nanoparticles: Mechanism of Antimicrobial Action, Synthesis, Medical Applications, and Toxicity Effects." Int Nano Lett. 2 (32): 1-10.

[17] Ben-Salem, A. N., Zyed. R., Mohamed L. A., Nidhal, S., Souad, S., and Mahjoub, A. 2012. "Cytotoxic Effect of Nanoparticles Synthesized from Salvia officinalis L. and
Ricinus Communis Aqueous Extracts against Vero Cell Line and Evaluation of Their Antioxidant Activities." Afr. J. Biotechnol 11 (52): 11530-4.

[18] Hussein, N. H., Shaarawy, H. H., Hawash, S. I., and Abdel-Kader, A. E. 2018. "Green Synthesis of Silver Nano Particles Using Fenugreek Seeds Extract." Journal of Engineering and Applied Sciences 13: 2.

[19] Mimica-Dukić, N., Boža, P., Igić, R., Spasić-Adjanski, L. J., and Štajner, D. 2002. "Volatile Constituents of Wild Growing Salvia Species in Province Vojvodina in Serbia." J Essent Oil Bearing Plants 5: 19-29.

[20] Bozin, B., Mimica-Dukic, N., Samojlik, I., and Jovin, E. 2007. "Antimicrobial and Antioxidant Properties of Rosemary and Sage (Rosmarinus officinalis L. and Salvia officinalis L.) Essential Oil.” J. Agric Food Chem. 55: 7879-85.

[21] Egert, S., and Rimbach, G. 2011. "Which Sources of Flavonoids: Complex Diets or Dietary Supplements?" $A d v$ Nutr. 2: 8-14.

[22] Grzegorczyk, I., Matkowski, A., and Wysokińska, H. 2007. "Antioxidant Activity of Extracts from in Vitro Cultures of Salvia officinalis L." Food Chem. 104: 536-41.

[23] Jayapriya, E., and Lalitha, P. 2013. "Synthesis of Silver Nanoparticles Using Leaf Aqueous Extract of Ocimum basilicum (L.)." Int J Chemtech Res. 5 (6): 2985-92.

[24] Doughari, J. H. 2006. "Antimicrobial Activity of Tamarindusindica Linn." Trop J Pharm Res. 5 (2): 597-603.

[25] Shrivastava, S., Bera, T., Roy, A., Singh, G., Ramachandrarao, P., and Dash, D. 2007. "Characterization of Enhanced Antibacterial Effects of Novel Silver Nanoparticles.” Nanotechnology 18: 103-12.

[26] Nel, A. E., Mädler, L., Velegol, D., Xia, T., Hoek, E. M. V., Somasundaran, P., Klaessig, F., Castranova, V., and Thompson, M. 2009. "Understanding Biophysicochemical Interactions at the Nano-bio Interface." Nat Mater. 8: 543-57.

[27] Marambio-Jones, C., and Hoek, E. M. V. 2010. “A Review of the Antibacterial Effects of Silver Nanomaterials and Potential Implications for Human Health and the Environment." J Nanopart Res. 12: 1531-51.

[28] Liu, J. Y., Sonshine, D. A., Shervani, S., and Hurt, R. H. 2010. "Controlled Release of Biologically Active Silver from Nanosilver Surfaces." ACS Nano. 4: 6903-13.

[29] Soo-Hwan, K., Lee, H., Ryu, D., Choi, S., and Lee, D. 2011. "Antibacterial Activity of Silver-nanoparticles Against Staphylococcus aureus and Escherichia coli." J Korean Microbiol Biotechnol. 39 (1): 77-85.

[30] Ortiz, E. P., Ruiz, J. H. R., Márquez, E. A. H., Esparza, J. L., Cornejo, A. D., González, J. C. C., Cristóbal, L. F. E., and López, S. Y. R. 2017. "Dose-dependent Antimicrobial Activity of Silver Nanoparticles on Polycaprolactone 


\section{Extract on Some Pathogenic Bacteria}

Fibers against Gram-Positive and Gram-Negative Bacteria." Hindawi, J Nanomater. 6: 1-9.

[31] Buszewski, B., Railean-Plugaru, V., Pomastowski, P., Rafińska, K., Szultka-Mlynska, M., Golinska, P., Wypij, M., Laskowski, D., and Dahm, H. 2018. "Antimicrobial Activity of Biosilver Nanoparticles Produced by a Novel Streptacidiphilus Durhamensis Strain.” J Microbiol Immunol Infect. 51 (1): 45-54.

[32] Wood, T. K. 2009. "Insights on Escherichia coli Biofilm Formation and Inhibition from Whole-Transcriptome Profiling." Environ Microbiol. 11 (1): 1-15.
[33] Kumar, P., Senthamilselvi, S., Lakshmipraba, A., Premkumar, K., Muthukumaran, R., Visvanathan, P., Ganeshkumar, R. S., and Govindaraju, M. 2012. "Efficacy of Bio-synthsized Silver Nanoparticles Using Acanthophora Spicifera to Encumber Biofilm Formation.' Dig J Nanomater Biostruct. 7 (2): 511-22.

[34] Namasivayam, S. K. R., Preethi, M., Bharani, A., Robin, G., and Latha, B. 2012. "Biofilm Inhibitory Effect of Silver Nanoparticles Coated Catheter against Staphylococcus aureus and Evaluation of Its Synergistic Effects with Antibiotics." Int J Biol Pharm Res. 3: 259-65. 